\title{
Referral Patterns of Patients with Limbal Stem Cell Deficiency to a Specialized Tertiary Center in the United Kingdom
}

\author{
Cristian Cartes · Majlinda Lako · Francisco C. Figueiredo
}

Received: March 28, 2021 / Accepted: April 27, 2021 / Published online: May 17, 2021

(C) The Author(s) 2021

\begin{abstract}
Introduction: Limbal stem cell deficiency (LSCD) is a potentially blinding disease; hence, referral to a specialist service is becoming increasingly common. Our aim was to investigate the referral patterns and associated details. Methods: We conducted an audit of 100 consecutive patients with LSCD who were referred to our service from 2011 to 2018. Patient demographics, geographical location, cause of LSCD, coexisting ocular diseases, best corrected visual acuity (BCVA), and extent of LSCD were recorded. The following two subgroups were further analyzed: (1) burns and (2) other causes of LSCD.

Results: Out of the 100 patients (138 eyes), $70 \%$ were male, with a mean age of 45 years (SD 19). LSCD was unilateral in $62 \%$ of the cases.
\end{abstract}

C. Cartes · F. C. Figueiredo Department of Ophthalmology Royal Victoria Infirmary, Newcastle Upon Tyne Hospitals NHS Foundation Trust, Newcastle upon Tyne, UK

M. Lako · F. C. Figueiredo ( $\square)$

Faculty of Medical Sciences, Bioscience Institute, Newcastle University, Newcastle upon Tyne, UK e-mail: francisco.figueiredo@newcastle.ac.uk
The most common ocular comorbidity was glaucoma, in 21 patients (33 eyes). Burns were the most frequent cause of referral (61\%). The mean BCVA of the involved eye was 1.22 (SD 0.8) LogMAR, and total LSCD was present in 75 eyes $(54 \%)$. There were statistically significant age, gender and eye-involved differences between the burns group and other causes group, mean 39 (SD 17) and 53 (SD 19) years $(p<0.001) ; 85 \%$ were men versus $48.7 \%$, $(p=0.001)$; and $82 \%$ were unilateral versus $31 \%$ $(p<0.001)$, respectively.

Conclusions: LSCD was more common in men and usually unilateral. Overall, the main cause of LSCD was burns. There were significant differences between the burns group and other causes of LSCD group in terms of age, gender and unilateral involvement that may help to guide management decisions.

Keywords: Chemical assault; Demographics; Eye burns; Limbal stem cells; Referral pattern 


\section{Key Summary Points}

Limbal stem cell deficiency (LSCD) is a serious blinding disease, and limited availability of treatment generates frequent referrals to a few highly specialized centers.

This is the first study that describes the referral pattern of LSCD patients in the UK and Europe. Burns are the most frequent cause of referral, and the demographics appear to be related to the etiology. Assault with ammonia has emerged as an important mechanism of LSCD.

Other etiologies of LSCD may result from preventable causes such as the use of topical mitomycin $\mathrm{C}$ and chronic use of topical medication with preservatives, which therefore should be avoided when possible.

Patients often have to travel long distances to be treated, and the required travel may represent a significant barrier to early tertiary referrals, or sometimes even late referrals.

\section{DIGITAL FEATURES}

This article is published with digital features, including a summary slide, to facilitate understanding of the article. To view digital features for this article go to https://doi.org/10.6084/ m9.figshare.14483754.

\section{INTRODUCTION}

Limbal stem cell deficiency (LSCD) results from a loss or deficiency of the corneal epithelial stem cells located in the limbus, causing invasion of the corneal surface by the adjacent conjunctival epithelium, so called conjunctivalization [1-3]. Clinically, LSCD is characterized by recurrent epithelial breakdown and impaired corneal healing, which may lead to persistent ocular surface inflammation and subsequent scarring, with consequent opacification and vascularization of the cornea [4]. Although total LSCD is known to result in severe visual impairment, partial LSCD may also cause major visual disturbances, depending on the extent of central corneal involvement [5]. This qualifies LSCD as a severe eye problem with a calculated incidence of 240 new cases per year in the UK, most of which are caused by chemical burns [6, 7]. LSCD related to burns has been defined as an orphan disease in the European Union (EU) [8]. Since LSCD is an orphan disease, there is limited information about it, and the information that is available is derived mostly from a few tertiary referrals centers [9]. Until recently, the available treatment was limited to transplantation of limbal tissue from the healthy eye in unilateral cases, including techniques such as conjunctival limbal autograft (CLAU), living related conjunctival limbal allograft (lr-CLAL), keratolimbal allograft (KLAL), simple limbal epithelial transplantation (SLET) and Boston Keratoprosthesis in some bilateral cases $[10,11]$. However, over the past 20 years, the development of limbal autologous cultivated cell transplant has improved LSCD treatment options, which has become available in a small number of centers throughout Europe, including the UK, resulting in referrals from all over the country [12]. Unfortunately, there is no information regarding the clinical features and demographics of patients with LSCD who are referred to specialized tertiary services in the UK, and similar information from other centers in the world is limited to only a few earlier publications $[9,13,14]$. We undertook this study to analyze the referral pattern of a tertiary referral center in the UK and characterize patients depending on the cause of their LSCD.

\section{METHODS}

Records were retrospectively reviewed for 100 consecutive LSCD patients referred to the LSCD Service at the Royal Victoria Infirmary (RVI), Ophthalmology Department, Newcastle upon 
Tyne, UK between January 2011 and December 2018. The diagnosis of LSCD was confirmed by a single specialist (FF) and was based on typical clinical signs, corneal impression cytology and in vivo confocal microscopy [15]. Variables, including age, gender, geographical location of the referral center, distance from patient's home address to RVI, referring doctor (general practitioner/ophthalmologist), eye involved, extension of LSCD, presence of ocular comorbidities and history of previous eye procedures related to LSCD, were recorded. Best corrected visual acuity (BCVA) was classified as mild visual loss $(>6 / 18)$, moderate visual loss (6/ $18-<6 / 60)$ and severe visual impairment $(\leq 6 /$ 60 ). The following two LSCD etiological classification-based subgroups were further investigated: (1) burns and (2) other causes of LSCD. This anonymized retrospective study was approved by the Clinical Governance and Audit Department of the Newcastle upon Tyne Hospitals NHS Foundation Trust (Ref: 10865); approved by the Caldicott Data Protection Guardian of the Newcastle upon Tyne Hospitals NHS Foundation Trust (Ref. 7963), and followed the tenets of the Declaration of Helsinki. Descriptive and comparative statistical analysis and chart preparation were done using Microsoft Excel (Microsoft Corporation, Redmond, Washington, USA) and SPSS 17.0 (IBM, Chicago, USA). The normality of the data distribution was assessed using the Shapiro-Wilk test, and parametric or non-parametric tests were used accordingly. Qualitative data were compared using Fisher's exact test. A value of $P<0.05$ was considered statistically significant. This anonymized retrospective audit was approved by the Clinical Governance and Audit Department of the Newcastle upon Tyne Hospitals NHS Foundation Trust (Ref: 10865); approved by the Caldicott Data Protection Guardian of the Newcastle upon Tyne Hospitals NHS Foundation Trust (Ref. 7963) and followed the tenets of the Declaration of Helsinki.

\section{RESULTS}

Of the 100 patients (138 eyes), 70 were male (70\%), with a mean age of 45 (SD 19; range
2-88) years. LSCD was unilateral in 62 patients $(62 \%)$. The most common ocular comorbidity was glaucoma, identified in 21 patients $(21 \%$, 33 eyes), who required regular topical treatment in $94 \%(31 / 33)$ and glaucoma surgery in $21 \%$ (7/ $33)$. In terms of LSCD cause, burns were the most frequent cause of referral in 61 patients (61\%). Figure 1 shows a summary of the different identifiable causes of unilateral and bilateral LSCD for the referred patients. The mean BCVA of the involved eye was 1.22 (SD 0.8) LogMAR and is grouped into three categories of visual loss (i.e. mild, moderate and severe) according to the cause of LSCD (Fig. 2) as described in the methods section. Total LSCD was present in 75 eyes (54\%), and partial LSCD was graded as (i) $<50 \%$ in 34 eyes (25\%) and (ii) between 50 and $75 \%$ in 29 eyes (21\%). Previous procedures related to the management of LSCD were noted in 34 patients $(34 \%)$, and the most common were (i) amniotic membrane in $17(17 \%)$, (ii) penetrating keratoplasty in 11 (11\%), (iii) botox/tarsorrhaphy in 4 (4\%), and (iv) previous stem cell transplant in $4(4 \%)$. Of the 100 patients, 93 were referred by an ophthalmologist and 7 by a general practitioner. With respect to location of the referral, the median of the distance was 53 (IQ 25-75\%=13-236) km, and excluding patients from the greater Newcastle area, it was 235 (IQ $25-75 \%=114-355$ ) $\mathrm{km}$. The geographical distribution of the referrals (UK and Europe) is illustrated in Fig. 3.

The burn group included 61 patients (72 eyes) with a mean age of 39 (SD 17; range 11-84) years, and 52 of them were male (85\%). Mean time of referral was 39.4 (SD 71) months. Unilateral involvement was reported in 50 patients (82\%). Regarding the mechanism, accident was the leading cause $(46 \%$-work-related in 33\% and domestic in 13\%), followed by assault (39\%), where alkali was the most frequent etiology. Burn causes and circumstances are summarized in Fig. 4 . The mean best corrected visual acuity (BCVA) in the affected eye was 1.2 (SD 0.9) LogMAR. Total LSCD was present in 50 eyes (69\%). Previous procedures related to the management of LSCD were noted in 21 patients (34\%) and the most common were (i) amniotic membrane in $20 \%$, (ii) penetrating keratoplasty in $9 \%$, (iii) 
A

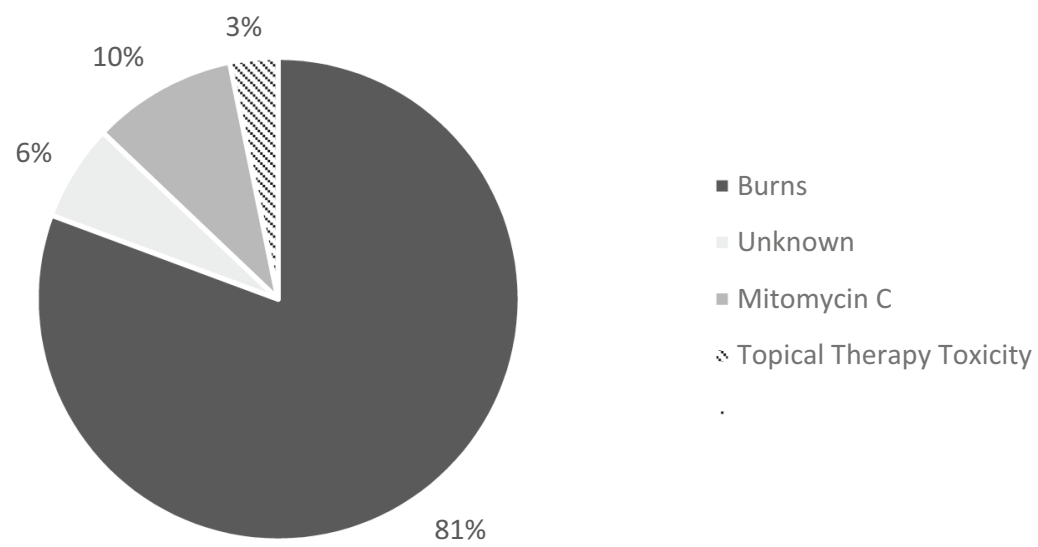

B

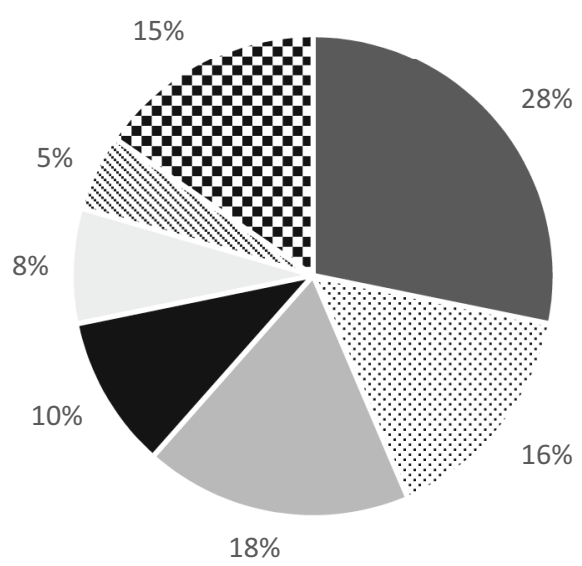

- Burns

$\therefore$ Unknown

- Aniridia

- Rosacea

Stevens-Johnson

$\therefore$ Topical Therapy Toxicity

- Others

Fig. 1 Unilateral (a) and bilateral (b) etiology of limbal stem cell deficiency (LSCD) referrals. Other causes include ocular cicatricial pemphigoid, chemotherapy, contact lens and neurotrophic keratopathy

botox/tarsorrhaphy in $7 \%$ and (iv) previous stem cell transplant in $3 \%$.

With respect to the chemical assault group, this affected 39\% of the burns group. The mean age was 37 (SD 12; 17-74) and 92\% were male. The mean BCVA of the affected eye was 1.2 (SD 0.7 ), and $33 \%$ were bilateral. Furthermore, 58\% $(n=14)$ of this group reported ammonia as the causal agent of the attack.

The other causes of LSCD subgroup included 39 patients (66 eyes), with a mean age of 53 (SD 19; range 2-88) years, and 19 were male (48.7\%). Unilateral involvement was found in
12 patients (31\%). The main cause of LSCD in this subgroup was aniridia in seven patients (18\%), followed by mitomycin C toxicity (ocular surface neoplasia and glaucoma in four and two patients, respectively) and other chronic topical therapy with preserved medication in six patients each (15\%). Previous procedures related to the management of LSCD were noted in 13 patients (33\%), and the most common were (i) amniotic membrane in $15 \%$, (ii) penetrating keratoplasty in $13 \%$ and (iii) previous stem cell transplant in 5\%. The comparison between the burn subgroup and other causes 


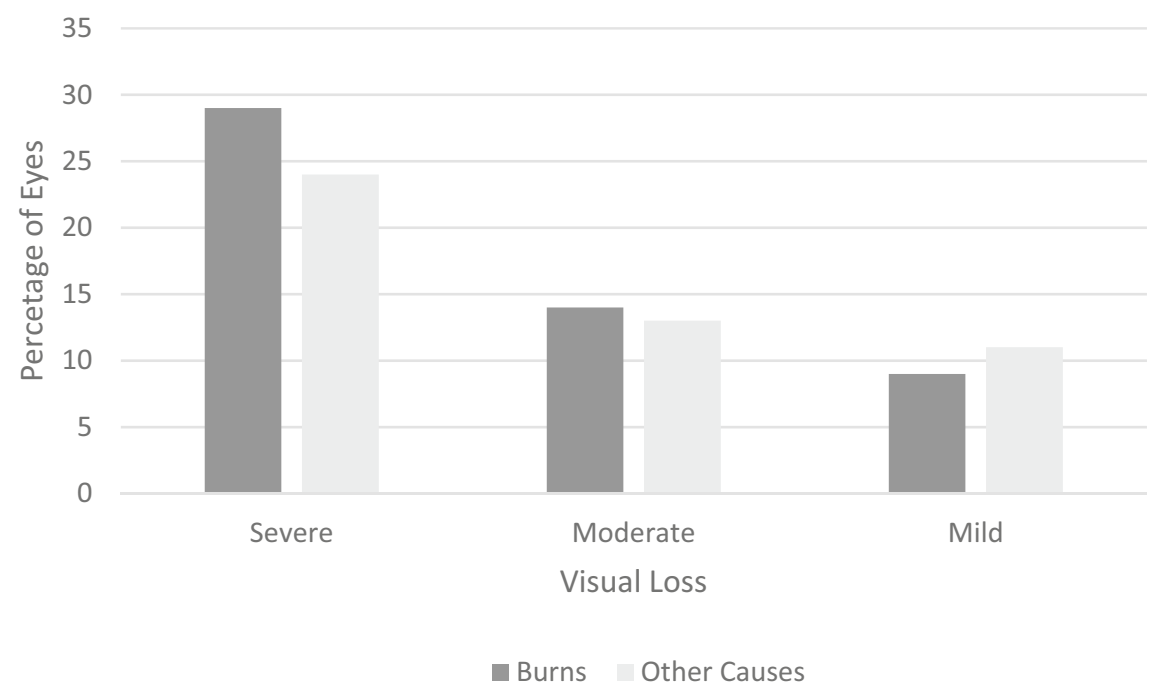

Fig. 2 Visual loss according to cause

subgroup is presented in Table 1 . There were statistically significant differences between the two subgroups in terms of age, gender, eye involved (unilateral vs bilateral) and extent of LSCD (partial vs total).

\section{DISCUSSION}

LSCD is a serious disease with a devastating impact on vision and quality of life $[16,17]$. Although there is evidence of increasing research in this area, unfortunately there are still very few specialized services providing treatment for LSCD in the world, including the UK. Therefore, there is limited information regarding the clinical and demographic features of patients referred to a specialized tertiary treatment center for the management of LSCD, and most of the cohort only consider clinical criteria to define $\operatorname{LSCD}[9,18,19]$. In fact, there are no such data reported in the UK. The causes of LSCD are heterogeneous, but a recently published case series from India described that the main cause of LSCD referral was burns, and they also reported that patients suffering from chemical burns have features differing from those seen in patients with LSCD due to other causes [9].

Overall, we found that LSCD was more common in young men, and the majority of cases were unilateral, similar to earlier reports $[9,11]$. It is important to recognize that those observations are directly related to the underlying cause of LSCD and may vary depending on local factors, and in this specific case series seem to be dependent on the relative proportion of eye burns in relation to the total number of referred LSCD patients. Additionally, in this study, BCVA at presentation was severely impaired $(\leq 6 / 60)$ in a high percentage of the patients. Although this seems to be a typical feature of patients with severe LSCD, it should be recognized that this series includes patients that had been referred to a tertiary treatment center; therefore, it is possible that this spectrum of severity may be overrepresented in this population.

The main cause of LSCD in our study was eye burns, especially chemical, and LSCD caused by burns seems to form a special group, affecting primarily young men. Also, a high percentage of this group allegedly had been assaulted. Assault with chemicals has become an increasingly common form of attack in certain areas of the UK, raising significant concerns [7]. Based on this scenario, our study describes an emerging health problem secondary to a violent behavior, affecting mainly young men due to attack, particularly containing ammonia resulting in significant visual loss and consequently 


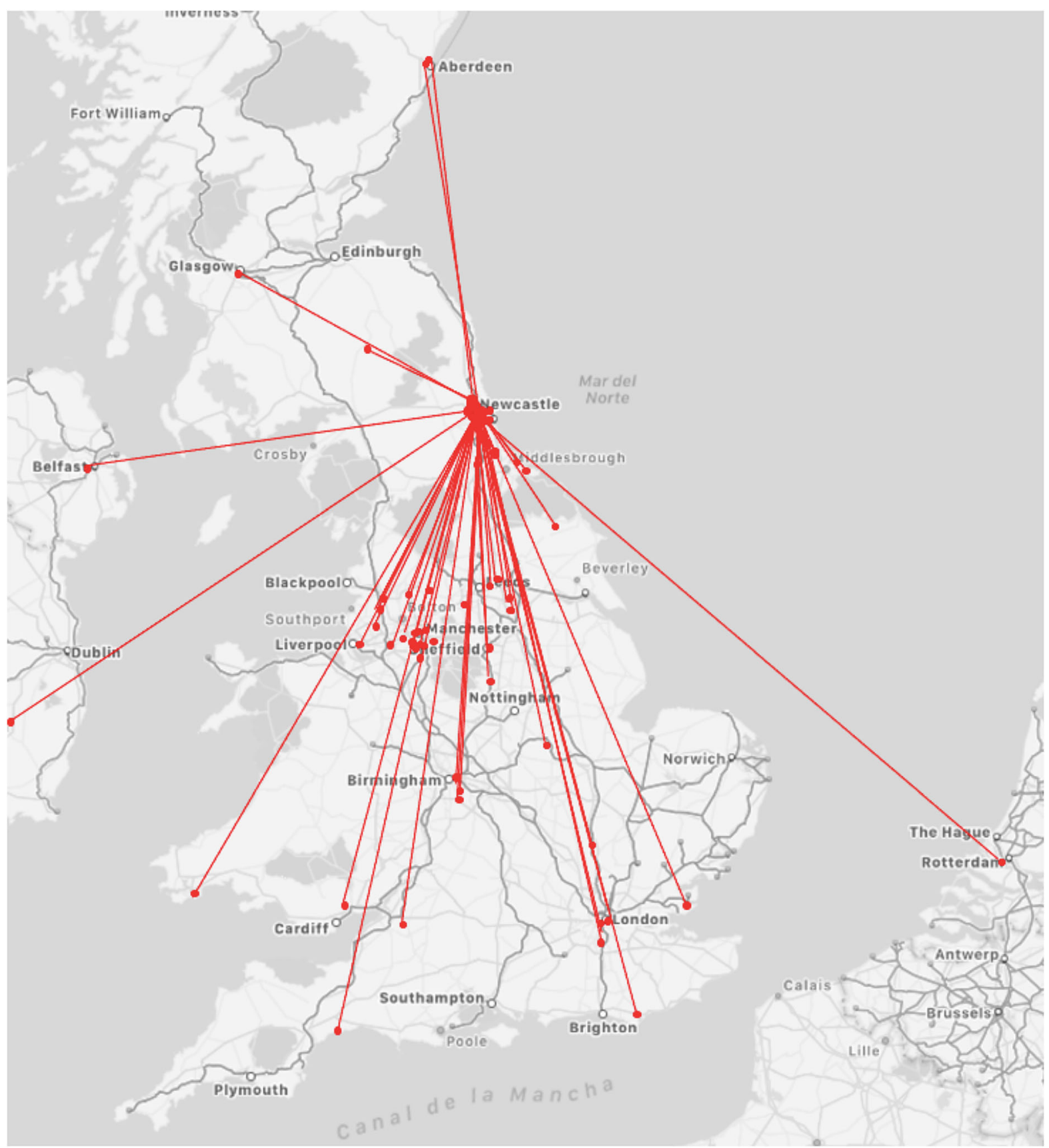

Fig. 3 Geographical distribution of the LSCD referrals (UK and Europe). LSCD Limbal stem cell deficiency. Source: adapted from Google Maps

impacting on different aspects of quality of life on the victims.

With respect to clinical features, most of the cases were unilateral, with severely impaired BCVA in just over half of the eyes, and almost $80 \%$ presented with signs of total LSCD. This results were similar to those described by Vazirani et al., who found that burns were the leading cause of unilateral LSCD [9]. Furthermore, a high percentage of patients presented with ocular comorbidities, such as glaucoma, that may affect the overall management and 
A

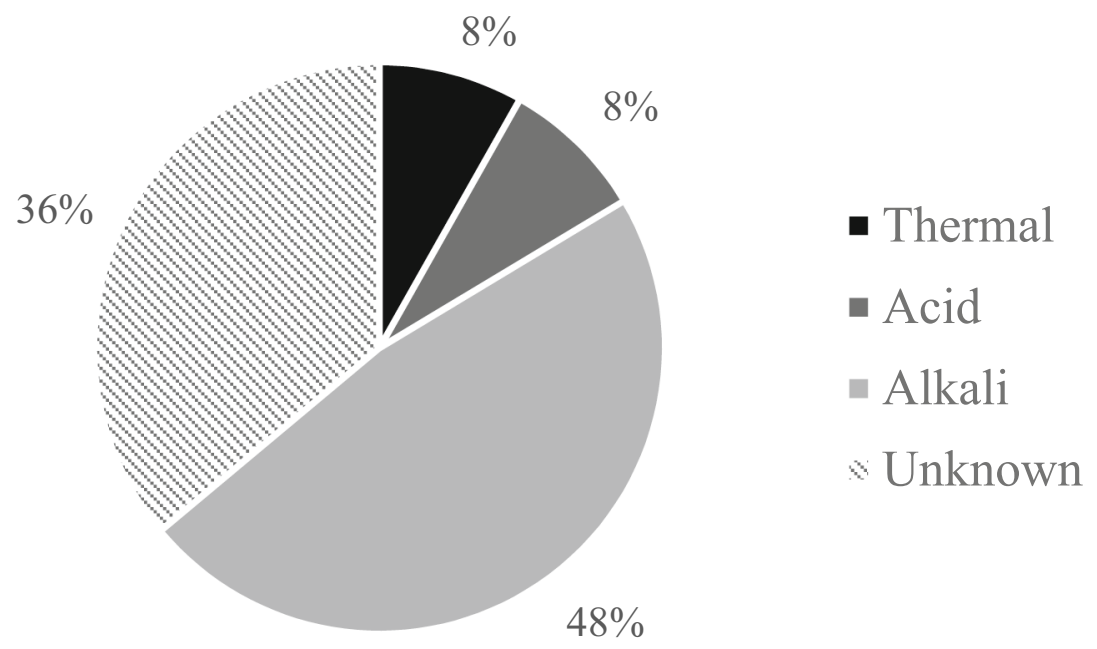

B

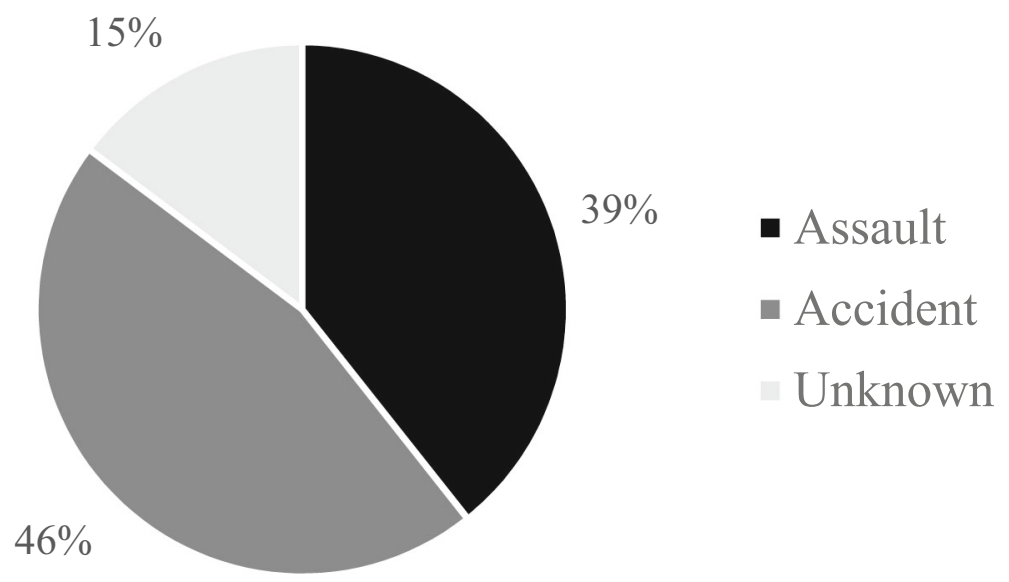

Fig. 4 Causal agent (a) and circumstances (b) of burn

final treatment outcomes. In addition, this group of patients were more likely to require surgical intervention; in fact, before referral, more than a third of the patients had already received one or more surgical interventions.

It is interesting that the highest proportion of referrals resulted from cases of chemical eye burns; while this trend can be explained by the recently reported increased incidence of chemical burns in the UK [7], it could also have occurred because of the recent awareness of new cell therapy treatment availability, especially in cases with severe LSCD, despite being unilateral $[20,21]$ or bilateral $[22,23]$. However, it is important to have in mind a prolonged referral time in many cases. Considering the devastating visual and quality of life consequences added by the cost of management of LSCD 
Table 1 Comparison between the chemical burn and other causes group

\begin{tabular}{lllr}
\hline & Burns $(\boldsymbol{N}=\mathbf{7 2}$ eyes $)$ & Other Causes $(\boldsymbol{N}=\mathbf{6 6}$ eyes $)$ & $\boldsymbol{p}$ value \\
\hline BCVA logMAR-mean (SD) & $1.2(0.8)$ & $1.1(0.8)$ & 0.3 \\
Age-mean years (SD) & $39(17)$ & $53(19)$ & $<0.001$ \\
Gender-Male \% & 85 & 48.7 & 0.001 \\
Unilateral involvement-\% & 82 & 31 & $<0.001$ \\
Total LSCD-eyes \% & 69 & 38 & $<0.001$ \\
Referral distance in km-median (IQ 25-75\%) & $60(6.9-245)$ & $53(23-231)$ & 0.8 \\
\hline
\end{tabular}

$B C V A$ best corrected visual acuity, $S D$ standard deviation, $L S C D$ limbal stem cell deficiency, $k m$ kilometers

caused by chemical burns [24], primary prevention should be prioritized locally [25].

The other causes of LSCD group in our study presented different features, probably because the etiology of LSCD is extremely diverse. In this group, the percentage female was higher, and the mean age of referral was also much higher when compared with the LSCD group caused by eye burns. It is important to note that visual deterioration was extremely serious in this group, as half of the eyes had BCVA worse than or equal to 6/60; total LSCD was present in one-third of the cases, and there was a high percentage of bilateral eye involvement, in which management is usually more challenging but also the higher impact on cost and quality of life [23]. Ocular comorbidities were also an important problem in this group, the most common being glaucoma. Although most of the causes were deemed not preventable, it is rather important to highlight the serious damage to the ocular surface caused by topical mitomycin $\mathrm{C}$ often used in glaucoma procedures and as topical chemotherapy, and chronic use of preserved topical medications such as in patients with glaucoma, in order to prevent the iatrogenic development of LSCD [26]. We believe that those risks should be discussed with patients before beginning a long-term treatment regime with a medication with wellknown ocular surface toxicity.

With respect to referral source, we received patients from all over the UK, with the majority being referred by an ophthalmologist. Unfortunately, specialized eye centers for the management of LSCD are not widely available in the
UK. This explains why patients often have to travel long distances to be treated; and unfortunately, the required travel may represent a significant barrier to early tertiary referrals, or sometimes even late referrals. However, in locations where local management of patients with LSCD is not available, we would like to emphasize the importance of early referral to a specialized tertiary LSCD treatment center to potentially reduce the risk of more significant corneal opacity due to chronic ocular surface inflammation, and consequently the need for a subsequent corneal transplantation after cell therapy. In this regard, there is an unmet need to develop an important educational awareness program all over the country to facilitate the establishment of a national consensus and easy referral process. In addition, it is also important that vision-threatening comorbidities such as glaucoma should receive prompt attention so as to avoid nonreversible visual loss.

Some of the limitations of our study are related to its retrospective design; as there is a risk that some of the comorbidities may have been underreported and the cause or mechanism of the damage, especially in the burns group, may not have been fully recognized. Moreover, this study represents the experience of one center and the results do not necessarily represent the whole picture in the UK; for instance, we have a reduced number of pediatric LSCD referrals. Nevertheless, we believe that this article is an initial effort to describe LSCD in the UK and adds valuable information in order to raise important awareness on this devastating orphan disease and the need for early referral of 
all moderate/severe LSCD patients, but also to report the different clinical presentation and patterns associated with the different groups; furthermore, in cases where prevention is possible, the information from our study can be used to help identify and avoid potential causes of harm. Although there are previous reports, most of them diagnose LSCD based only on slit lamp clinical examination. However, our study has the additional advantage that all patients had adjunct diagnostic tests, such as impression cytology and in vivo confocal microscopy, to confirm the diagnosis of LSCD.

\section{CONCLUSIONS}

In conclusion, this study describes the referral pattern of LSCD patients to a specialized LSCD tertiary treatment center in the UK and provides useful information that could lead to establishment of a national referral guideline, but also to different prevention and treatment strategies for an infrequent but potentially blinding disease.

\section{ACKNOWLEDGEMENTS}

Funding. No funding or sponsorship was received for this study. The Rapid Service Publication Fee was funded by Research FundNewcastle upon Tyne Hospitals NHS Foundation Trust, Newcastle upon Tyne, UK.

Authorship. All named authors meet the International Committee of Medical Journal Editors (ICMJE) criteria for authorship for this article, take responsibility for the integrity of the work as a whole, and have given their approval for this version to be published.

Authors Contributions. Study conception and design: Cristian Cartes, Majlinda Lako, Francisco C Figueiredo; Data Collection: Cristian Cartes; analysis and interpretation of the results: Cristian Cartes, Francisco C Figueiredo; draft manuscript preparation: Cristian Cartes, Majlinda Lako, Francisco C Figueiredo.
Disclosures. Cristian Cartes, Majlinda Lako and Francisco C Figueiredo have no conflict of interest to declare.

Compliance with ethics guidelines. This anonymized retrospective audit was approved by the Clinical Governance and Audit Department of the Newcastle upon Tyne Hospitals NHS Foundation Trust (Ref: 10865); approved by the Caldicott Data Protection Guardian of the Newcastle upon Tyne Hospitals NHS Foundation Trust (Ref. 7963) and followed the tenets of the Declaration of Helsinki. We thank the participants of the study.

Data Availability. The data analyzed during the current study are available from the corresponding author on reasonable request.

Open Access. This article is licensed under a Creative Commons Attribution-NonCommercial 4.0 International License, which permits any non-commercial use, sharing, adaptation, distribution and reproduction in any medium or format, as long as you give appropriate credit to the original author(s) and the source, provide a link to the Creative Commons licence, and indicate if changes were made. The images or other third party material in this article are included in the article's Creative Commons licence, unless indicated otherwise in a credit line to the material. If material is not included in the article's Creative Commons licence and your intended use is not permitted by statutory regulation or exceeds the permitted use, you will need to obtain permission directly from the copyright holder. To view a copy of this licence, visit http://creativecommons.org/licenses/by$\mathrm{nc} / 4.0 /$.

\section{REFERENCES}

1. Kinoshita S, Kiorpes TC, Friend J, Thoft RA. Limbal epithelium in ocular surface wound healing. Invest Ophthalmol Vis Sci. 1982;23: 73-80. Available: http://www.ncbi.nlm.nih.gov/pubmed/7085223

2. Puangsricharern V, Tseng SC. Cytologic evidence of corneal diseases with limbal stem cell deficiency. 
Ophthalmology. 1995;102:1476-85. https://doi. org/10.1016/s0161-6420(95)30842-1.

3. Deng SX, Borderie V, Chan CC, Dana R, Figueiredo FC, Gomes JAP, et al. Global consensus on definition, classification, diagnosis, and staging of limbal stem cell deficiency. Cornea. 2019;38:364-75. https://doi.org/10.1097/ICO.0000000000001820.

4. Dua HS, Azuara-Blanco A. Limbal stem cells of the corneal epithelium. Surv Ophthalmol. 2000;44: 415-25. https://doi.org/10.1016/s00396257(00)00109-0.

5. Dua HS, Saini JS, Azuara-Blanco A, Gupta P. Limbal stem cell deficiency: concept, aetiology, clinical presentation, diagnosis and management. Indian J Ophthalmol. 2000;48: 83-92. Available: http:// www.ncbi.nlm.nih.gov/pubmed/11116520

6. Shortt AJ, Tuft SJ, Daniels JT. Corneal stem cells in the eye clinic. Br Med Bull. 2011;100:209-25. https://doi.org/10.1093/bmb/ldr041.

7. Ghosh S, Salvador-Culla B, Kotagiri A, Pushpoth S, Tey A, Johnson ZK, et al. Acute chemical eye injury and limbal stem cell deficiency-a prospective study in the United Kingdom. Cornea. 2019;38: $8-12$. 0000000000001739.

8. European Medicine Agencys. 2020. https://www. ema.europa.eu/en/medicines/human/orphandesignations/eu308579. Accessed Mar 2020

9. Vazirani J, Nair D, Shanbhag S, Wurity S, Ranjan A, Sangwan V. Limbal stem cell deficiency-demography and underlying causes. Am J Ophthalmol. 2018;188:99-103. https://doi.org/10.1016/j.ajo. 2018.01.020.

10. Sejpal K, Yu F, Aldave AJ. The Boston keratoprosthesis in the management of corneal limbal stem cell deficiency. Cornea. 2011;30:1187-94. https:// doi.org/10.1097/ICO.0b013e3182114467.

11. Vazirani J, Ali MH, Sharma N, Gupta N, Mittal V, Atallah M, et al. Autologous simple limbal epithelial transplantation for unilateral limbal stem cell deficiency: multicentre results. Br J Ophthalmol. 2016;100:1416-20. https://doi.org/10.1136/ bjophthalmol-2015-307348.

12. Pellegrini G, Traverso CE, Franzi AT, Zingirian M, Cancedda R, De Luca M. Long-term restoration of damaged corneal surfaces with autologous cultivated corneal epithelium. Lancet. 1997;349:990-3. https://doi.org/10.1016/S0140-6736(96)11188-0.

13. Cauchi PA, Ang GS, Azuara-Blanco A, Burr JM. A systematic literature review of surgical interventions for limbal stem cell deficiency in humans. Am
J Ophthalmol. 2008;146(251-259):e2. https://doi. org/10.1016/j.ajo.2008.03.018.

14. Rama P, Matuska S, Paganoni G, Spinelli A, De Luca M, Pellegrini G. Limbal stem-cell therapy and longterm corneal regeneration. N Engl J Med. 2010;363: 147-55. https://doi.org/10.1056/NEJMoa0905955.

15. Jawaheer L, Anijeet D, Ramaesh K. Diagnostic criteria for limbal stem cell deficiency-a systematic literature review. Surv Ophthalmol. 2017;62: 522-32. https://doi.org/10.1016/j.survophthal. 2016.11.003.

16. Sangwan VS, Basu S, Vemuganti GK, Sejpal K, Subramaniam SV, Bandyopadhyay S, et al. Clinical outcomes of xeno-free autologous cultivated limbal epithelial transplantation: a 10-year study. Br J Ophthalmol. 2011;95:1525-9. https://doi.org/10. 1136/bjophthalmol-2011-300352.

17. Chan CC, Holland EJ. Severe limbal stem cell deficiency from contact lens wear: patient clinical features. Am J Ophthalmol. 2013;155(544-549):e2. https://doi.org/10.1016/j.ajo.2012.09.013.

18. Basu S, Fernandez MM, Das S, Gaddipati S, Vemuganti GK, Sangwan VS. Clinical outcomes of xenofree allogeneic cultivated limbal epithelial transplantation for bilateral limbal stem cell deficiency. Br J Ophthalmol. 2012;96:1504-9. https://doi.org/ 10.1136/bjophthalmol-2012-301869.

19. Bobba S, Di Girolamo N, Mills R, Daniell M, Chan E, Harkin DG, et al. Nature and incidence of severe limbal stem cell deficiency in Australia and New Zealand. Clin Exp Ophthalmol. 2017;45:174-81. https://doi.org/10.1111/ceo.12813.

20. Vazirani J, Basu S, Kenia H, Ali MH, Kacham S, Mariappan I, et al. Unilateral partial limbal stem cell deficiency: contralateral versus ipsilateral autologous cultivated limbal epithelial transplantation. Am J Ophthalmol. 2014;157(584-590):e2. https://doi.org/10.1016/j.ajo.2013.11.011.

21. Basu S, Sureka SP, Shanbhag SS, Kethiri AR, Singh V, Sangwan VS. Simple limbal epithelial transplantation: long-term clinical outcomes in 125 cases of unilateral chronic ocular surface burns. Ophthalmology. 2016;123:1000-10. https://doi.org/10. 1016/j.ophtha.2015.12.042.

22. Sotozono C, Inatomi T, Nakamura T, Koizumi N, Yokoi N, Ueta M, et al. Visual improvement after cultivated oral mucosal epithelial transplantation. Ophthalmology. 2013;120:193-200. https://doi. org/10.1016/j.ophtha.2012.07.053.

23. Vazirani J, Mariappan I, Ramamurthy S, Fatima S, Basu S, Sangwan VS. Surgical management of bilateral limbal stem cell deficiency. Ocul Surf. 
2016;14:350-64. https://doi.org/10.1016/j.jtos. 2016.02.006.

24. Economic impact of acid attacks in the UK. 2020. https://www.frontier-economics.com/media/1138/ 20180709_economic-impact-of-acid-attacks-in-theuk_frontier.pdf. Accessed Mar 2020
25. Whitcher JP, Srinivasan M, Upadhyay MP. Corneal blindness: a global perspective. Bull World Health Organ. 2001;79: 214-21. Available: http://www. ncbi.nlm.nih.gov/pubmed/11285665

26. Muthusamy K, Tuft SJ. Iatrogenic limbal stem cell deficiency following drainage surgery for glaucoma. Can J Ophthalmol. 2018;53:574-9. https://doi.org/ 10.1016/j.jcjo.2018.01.037. 